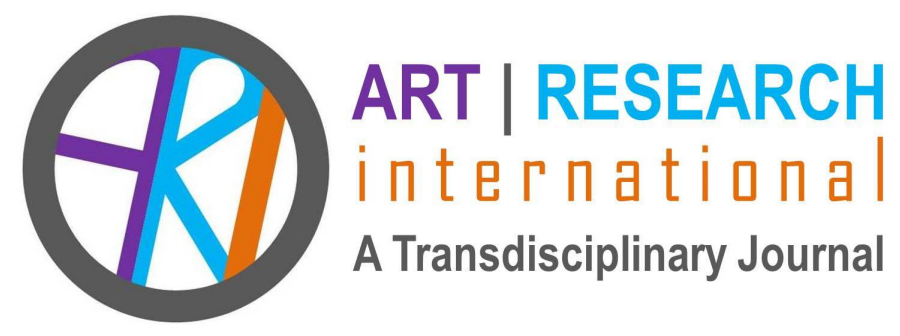

\title{
BOOK PUBLICATION AS PEDAGOGY: TAKING LEARNING DEEP AND WIDE
}

\section{Lisa Stoneman Roanoke College Education Department stoneman@roanoke.edu}

\author{
DorothyBelle Poli \\ Roanoke College Biology Department \\ poli@roanoke.edu
}

Anna Denisch amdenisch@mail.roanoke.edu

Lydia Weltmann roseweltmann@gmail.com

Melanie Almeder Roanoke College English \& Communication Studies Department almeder@roanoke.edu

Lisa Stoneman specializes in English pedagogy. Her interests include democratic education, and folklore, particularly that of the Celtic and Appalachian regions. She is currently involved in interdisciplinary research projects that bridge education folklore and science. She teaches disciplinary literacy and general education courses, as well as supervising students in the field. 
DorothyBelle Poli is an evolutionary biologist who specializes in plant physiology with a research focus on fossil plants. Currently she teaches cell biology, evolution, and plant diversity. She also is a Research Assistant at the Virginia Museum of Natural History in Martinsville VA where she studies the Commonwealth's paleobotany collection.

Anna Denisch was born and raised right outside Baltimore, MD. She spent six years studying writing and along the way spent countless hours researching the lore of dragons and the science behind their mythical origins. She also knows far too much about boat architecture for someone who has never set foot on one.

Lydia Weltmann studied Creative Writing at Roanoke College. She originally joined the Dragon Research Collaborative to search out dragon folk tales from around the world. She later combined her passion for writing with the research she'd already done and is creating a trilogy of novellas based on the various mythologies.

Melanie Almeder's first book of poems, On Dream Street, won the Tupelo Press Editor's Prize. Her individual poems have been published in a range of journals, including Poetry, 32Poems, The Seneca Review, and The American Literary Review. In addition, her essays on contemporary art have appeared in exhibitions in the U.S. and abroad.

Abstract: For students, the practice of writing, illustrating, and publishing facilitates deep learning experiences, both within and beyond the discipline for which the writing is targeted. In this case study, students created books under the umbrella of a large, transdisciplinary research project: a science-based, illustrated activity book, a children's fiction chapter book with illustrations, an adolescent novel, and two illustrated social studies activity books. Students completed the self-directed research, wrote the narratives, created the artwork, sought the advice of outside scholars and artists, and revised with discipline-specific mentors. Data include the books, mentor notes, and student-reported learning outcomes. Data reveal broad content and pedagogical skill knowledge acquisition, knowledge synthesis, and a deep level of self-authorship.

Keywords: self-authorship, authentic learning, transdisciplinary, critical thinking 
Create: to bring into existence; the power contained in the word helps to explain why book development is such a transformational learning experience (Emig, 1988; Ensio \& Boxeth, 2000). To bring something new into being is bound to fill one with a deep sense of accomplishment. It is an inclusive process that affects not only the learner engaged in the creation of the book, but also those engaged with the creator during (Dartmouth, 2016) and after the process (Michigan State University, 2016).

The act of writing is not solely a communication form; it can facilitate deep learning experiences, both within and beyond the discipline within which the writing resides (Odell, 1980). Janet Emig explains this power in her 1977 treatise, Writing as a Mode of Learning: "writing is epigenetic, with the complex evolutionary development of thought steadily and graphically visible and available throughout as a record of the journey, from jottings and notes to full discursive formulations" (p. 127). Since the 1980s, the idea that each disciplinary domain should teach its adherents to write has gained favor, and writing instruction has become more distributed (Hamilton, 1980; McCloud, 1988). A number of higher education institutions (e.g. University of Massachusetts, University of Richmond, George Mason University, University of Pittsburgh, Purdue University) have embraced this distribution, creating hubs to coordinate writing/learning resources for students and faculty.

Using the practice of writing as a pedagogical tool is well ...the artist and the writer work together to consider their purpose when drafting, revising, and finalizing a piece, immersing themselves in the pedagogical and creative processes simultaneously. established in the literature (Bean, 2001; Emig, 1988; National Survey of Student Engagement, 2008; Zinsser, 1988). Though the humanities had long been the bastion of traditional writing instruction, the multidisciplinary literacy effort reached out early to include the STEM fields. However, implementation in those disciplines has met with some resistance, even though there is literature to support its efficacy (Reynolds, Thaiss, Katkin, \& Thompson, 2012). Moore (1993) and Rivard (1994) describe how disciplinary-based writing is successfully used to facilitate science learning, while Brenson and Carter (1995) report enhanced student self-reflection and conceptual understanding in mathematics. Several bodies, including the American Association for the Advancement of Science (2011), call out the need for writing skill among scientists so that they might convey information to a wider population than themselves (National Research Council, 2012; President's Council of Advisors for Science and Technology, 2012).

Art, another form of communication, is also a catalyst for learning (Lucey and Laney, 2017; Pyle, 2000; Winrich, 1991;). It facilitates knowledge acquisition from a different logic or aesthetic perspective and may not only reach a wider student 
audience, but may enhance the conceptual knowledge of the artist as well (Graham, 1995; Sousanis, 2015). Children's books are often filled with art that can propel or even construct narrative without the need for text. In other cases, art serves to explicate the written word, or the two work synergistically in tandem. In either case, the artist and the writer work together to consider their purpose when drafting, revising, and finalizing a piece, immersing themselves in the pedagogical and creative processes simultaneously.

A number of disciplines endeavor to have their undergraduate students publish work, but that work is often in the form of articles or sections of articles written solely about the portion of the advisor's research for which the student has been responsible, and then, that writing is still primarily done by the mentor. Though this kind of writing is certainly instructional and can provide a sense of ownership to the student, it may not require the immersion or provide the self-authorship that creation and publication of a book-length product provides. Book publication is one way to authenticate student work, and research suggests that it has a number of benefits to the learner and the research environment. Student publication creates deeper conceptual understanding (Graves, 1984; Wess, 1980), provides transformational learning opportunities (Beers, 2000; Ensio \& Boxeth, 2000), and helps to build a foundation for continued research and creation (Lawrence, 1999). Given the pedagogical foundation for creating, and often publishing, student books in the $\mathrm{K}-12$ environment, it is surprising that the practice is not more widely established in higher education. This article reports the experiences of a multi-year case study of undergraduates, documenting the creation of five student books that served as transformative pedagogical tools.

\section{Methods}

Harry Wolcott (2005) states that "Collecting data can be done scientifically, but fieldwork consists of more than collecting data. Whatever constitutes that elusive "more" makes all the difference" (p. 5). In this case study, that more includes literature and cultural exploration, weekly research meetings, mentoring meetings, text editing, teaching, learning, and all the other parts of relationships that are built among a cohesive research group throughout several years of a project. The data that resulted from this study are thick and rich: students completed self-directed research, wrote narratives, created or collaborated on artwork, sought the advice of outside scholars, and revised with discipline-specific mentors. The authors were the sole generators of their texts; the mentors acted only in the editorial role, holding the authors accountable to deadlines, to structural integrity, to fact checking content, or to cleaning up syntax and grammar. Data include multiple drafts of each book, multiple pieces of artwork, mentor notes, and student-reported and facilitator observed learning outcomes. 
This study was embedded within a larger, ongoing project of the Dragon Research Collaborative (DRC). The DRC is a research team that focuses on a central hypothesis: Carboniferous plant fossils are connected to dragon folklore throughout the world (Poli \& Stoneman, 2017). All projects connect, at least tangentially, to this hypothesis. Many are directly related; others appear unconnected at first glance but may have arisen from an idea generated by the original hypothesis (Poli \& Stoneman, 2018).

\section{Development of a Science Activity Book}

This work was collaborative, yet largely in an asynchronous way. One undergraduate student completed a senior thesis project in biology, identifying the species of Carboniferous fossil plants in a state natural history museum collection. As part of the project, he drew all of the fossils under a camera lucida (a simple set of mirrors on a microscope that allow you to directly trace what you see onto a piece of paper) to assist in his identifications. These drawings became known to another biology student who was interested in using these fossil drawings to develop a story to teach K-12 students about plant evolution (Conter, Lumpkin, Poli, \& Stoneman, 2017).

The author (an art minor) decided to drive her narrative with a set of characters who would encourage the reader to move through the activities in the book. She was inspired by still another student artist's drawing of a DRC dragon mascot (male) and used that drawing as a model from which to create a female dragon character. Other cartoon-like characters, drawn from the author's re-visioning of several DRC members quickly followed and represented a cross-section of the team: male, female, professor, student, African American, Hispanic, and Caucasian.

During her process the author felt she needed to expand content beyond the extinct plants in the original artist's drawings. With the guidance of an evolutionary plant biologist, she outlined this additional content. She brought in a range of organisms, from green algal beginnings to angiosperms, focusing on life cycles, key evolutionary characters unique to particular groups, and how scientists use all data to develop their conclusions. In addition, the author chose to add information about how museums develop their collections. To accomplish this area of the task, she worked alongside a curator to ensure content accuracy. Finally, once she had full command of her content, the author worked with a pedagogy expert to construct age-appropriate, active exercises to complete the book. These exercises remained aligned with the content while also being grounded in solid pedagogical theory. Activities included dot-to-dot completions of fossils and live plants, fold overs that allowed readers to see plant 
symmetry, mazes that helped characters find one another, matching terms with drawings, and word games (Figure 1).

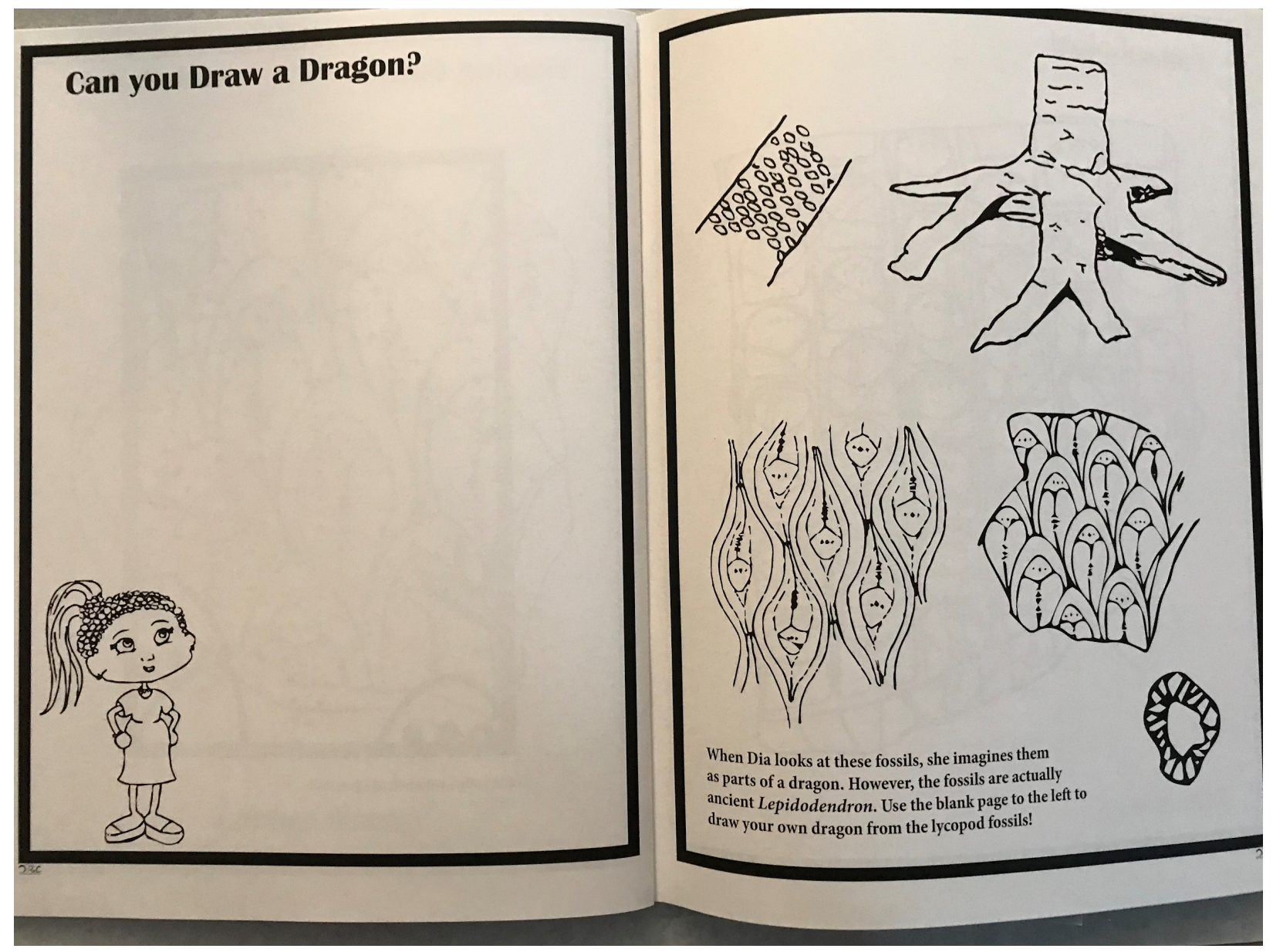

Figure 1. Illustrated activity from The Dragon's Guide to Plant Evolution (Conter, Lumpkin, Poli, \& Stoneman, 2017)

Once art, content, and activities were complete, the student author prepared all components for publication. She rendered all pages electronically, using the Huidon Pro pressure sensitive tablet, and then processed the images using Adobe Creative Cloud Suite, specifically Adobe Photoshop, Adobe Illustrator, and Adobe Indesign. Upon completion of the final product, additional students were found to help translate the activity book into several languages: Chinese, Twi, French, and Spanish.

\section{Development of Fantasy Children's/Adolescent Book Series}

This work began when a creative writing student, paid to search for and categorize dragon folklore, recruited a fellow writer to the project and shifted focus from literature searches to book development. The original plan was to write short stories 
related to a variety of dragon legends. At this initial stage, each author was writing a separate text related to dragon folklore, the children's book set in the modern age, the adolescent book in medieval, Africa. When the first story was in process, the authors realized the pragmatic and generative functions of regularly bouncing ideas off of one another, and collaborative planning and outlining ensued.

Africa is not a continent that the students knew as traditionally associated with dragons, so the writing process was time consuming and fraught with the problem of qualifying the lore. Harold Courlander's (1996), A Treasury of African Folklore, was used in this effort as it contained stories and oral histories from a variety of African countries. The authors are aware that the question of authenticity of lore has colonial attributes and is a point of contention (Finnegan, 2007). In this case, the students used this source for idea generation that spurred geographic exploration as well.

The next step was to use the folklore in developing individual chapters. Additional research into modern day African culture was needed, particularly with regard to the lives of the inhabitants of Zimbabwe as it is where a main character originates. This part of the research helped ensure that the books have a realistic tone; it also helped with authentic character development. For example, the main character of the children's series is a young girl named Choolew. Knowing that France had a large influence in early colonial Zimbabwe, it made sense for the character to speak French. This cultural information allowed the author to use the complex and dynamic nature of language to potentially drive later action and character development in the book and series.

At this point in the writing process, the need for deeper geography knowledge came into play. In the children's series, each book is set in different locations: Zimbabwe, South Africa, Benin, Wagadu (ancient Ghana), The Gambia, Tunisia, Libya, Egypt, and Ethiopia. Chapters are laid out in geographical order. For instance, the action begins in Zimbabwe, and moves clockwise around Africa to Ethiopia and across the Red Sea to the Middle East, where the second book of the modern adolescent series begins.

Both book series build from one another, so it was important for the authors to stay in close contact and work to ensure narrative consistency across books. Without this collaborative effort, a dragon slain in the medieval time period might still be alive in the modern series, causing dissonance to the storyline. This was accomplished in a number of ways. For instance, both authors remained authentic to the existing folklore narrative structures. If a folktale said the dragon was killed, then that dragon was slain in the medieval series and therefore became available to be "restored" in the modern, adolescent timeline. If the folklore was unclear on the issue, the authors created an online list to keep track of their dragon mortality decisions. 
Revisions were managed as closely as the original writing. For example, the authors asked critical questions in regard to use of magical elements across storylines: Was that use logistically appropriate, and if not, how might they handle the exceptions to the rule? This kind of collaborative process work took much outlining and reconstructing. The authors met once a week to write and discuss the series, typically spending one hour explicating concerns such as gaps in structural alignment and a second hour writing together, using word sprints (10-15 minutes of individual speed writing). It is noteworthy that the author of the adolescent book took her project into one of her creative writing courses as a class assignment. The children's book author chose to follow the same structured writing timeline to which they each held one another accountable.

\section{Development of Social Studies Activity Books}

In similar fashion to the science activity book, two history majors, one with an interest in events of the Middle Ages, and the other interested in the U. S. Civil Rights Movement, created activity books to address these topics. As both students were also secondary education minors, a middle/high school audience was chosen for both books. The authors began their research process by reflecting on the large body of information available on both topics and the need to qualify their foci. Overarching, umbrella concepts were chosen and rather than focusing solely on facts and dates, each author chose catalytic moments that drove change to help them refine to specific content. Both also chose to drive this content via an omniscient dragon narrator who would tell the story as he shared oral histories with his grand dragons.

Each author created an outline, then a storyboard, including the backstory narrative of how the dragon grandparent and children interacted throughout. From the storyboarding, each author developed interactive learning activities: word searches, mazes, matching questions, coded passages, etc. As part of this process, a list of visual representations needed for each book page was created. For example, the medieval era activity book required an illustration of Joan of Arc to go along with an activity that was specific to French geography (Figure 2). In the Civil Rights era book, a drawing of the Lincoln Monument illustrated a portion of the narration on catalysts of the movement. Once the historical content areas and illustration needs were identified, the authors met with an artist to whom they conveyed their big picture ideas: style of art, number of illustrations, and alignment of art with the two-level plotlines. The authors regularly checked decisions with their pedagogy mentor to ensure that clarity and focus on content were achieved. They also studied the Virginia Standards of Learning and 
found alignment points between their content and Standards across several grade levels and subject areas.

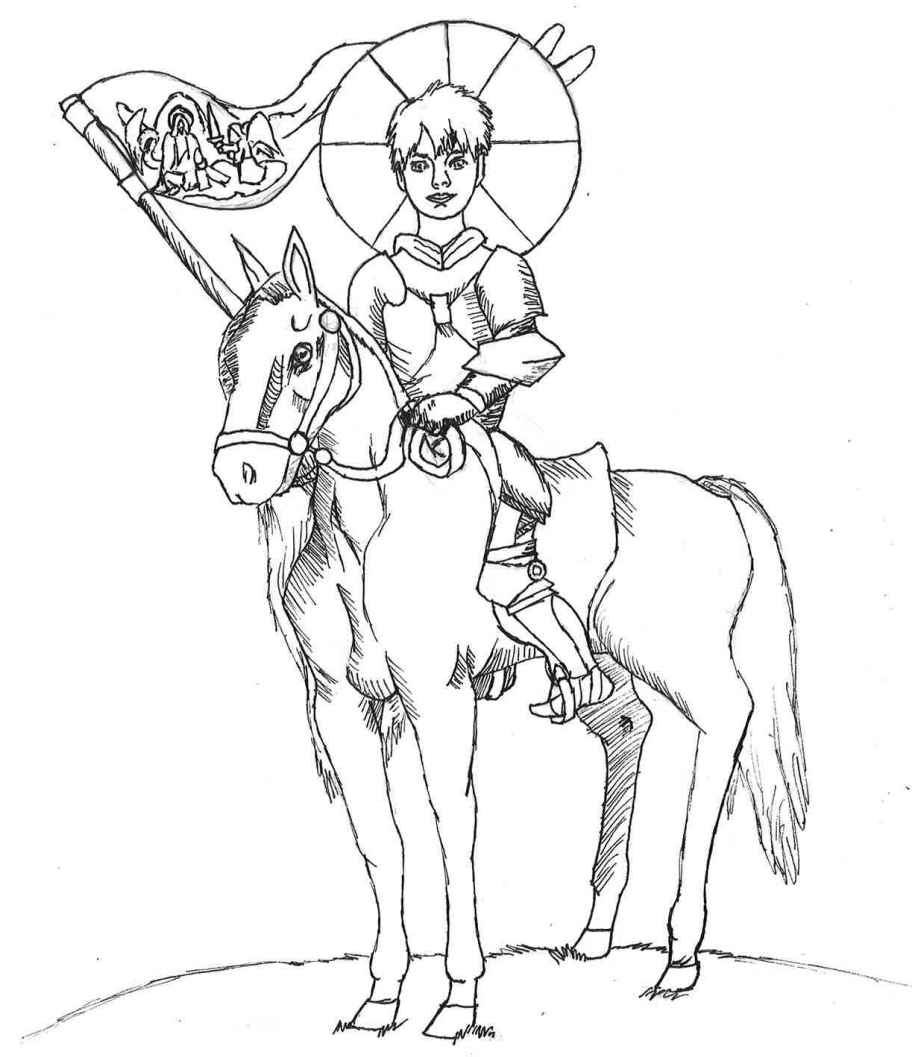

Figure 2. Illustration from history activity book: Joan of Arc. (Myers, Langheim, Stoneman, \& Poli, 2019)

Collaborating with the artists. Though both fantasy authors were writing about the same dragons, the stories were different in tone and setting. In addition, the adolescent book, set in the Middle Ages with a darker, more menacing tone, did not require in-text illustrations, though the author did work with an artist on the book cover. The same artist also designed and created the cover art for the children's book. The children's book author also required art at the beginning of chapters to help the reader visualize each dragon as they appeared in the narrative. She met with a different artist, sharing dragon descriptions from her text. The line drawings that were chosen to complement each chapter were also used in a coordinating coloring book by the same artist (Figure 3). 

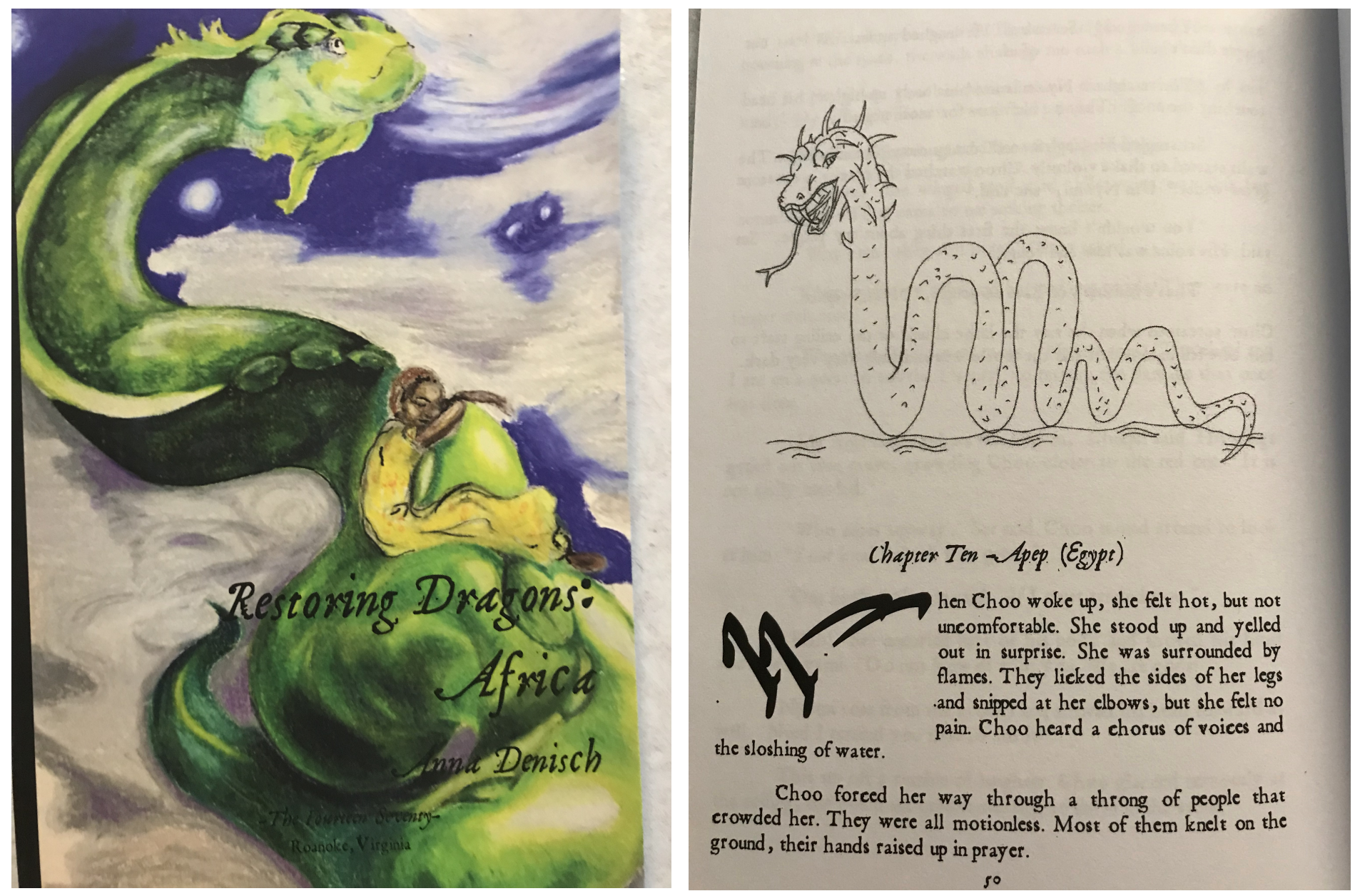

Figure 3a \& b. Cover and line art from Restoring Dragons: Africa (Denisch, 2016).

\section{Ready for Publication}

The science activity book was completed to publication standards by the author. She took it upon herself to find out what software was needed, worked with team leaders to acquire it, and became proficient with using it. She presented her print-ready manuscript to the state natural history museum and was accorded their approval and permission to apply their logo to the book's title page. Books were printed and sold in the museum's store.

The authors of the novels explored self-publishing. This process involved the guidance of a publishing professional to ensure the students gained accurate knowledge of the modern publishing business and process. The authors worked intensively with faculty in English and Modern Languages who had experience editing and publishing. In the end, the novels were published through the same state natural history museum as the science activity book. Even though these books were fictional, 
with the addition of an introduction and note to the reader tying the books back to the original DRC hypothesis, the museum felt their mission was met. The social studies activity book authors are exploring this publishing path as well and have pitched their books in process to the museum staff as a coordinated series with the science activity book already being sold at the museum.

In the case of the fiction series, the authors wanted to learn more thoroughly the skills of self-publication prior to releasing their second books in the series. Though they are no longer undergraduate students, utilizing their previous interactions on the team, they created a community of experts who still support their learning. In addition to an Amazon release, the authors' work will continue to be showcased at the state museum's store as well as at DRC events such as festivals and exhibits.

\section{Results}

\section{Books as Evidence of Content Knowledge}

The most tangible and rich data from this study are the books themselves. Within these products, we see evidence of the students' new content knowledge, application of that knowledge, and the implicit evidence of the skills that facilitated the learning. The students report that ownership of these projects and their ability to take something from idea stage to final product led to growth that went far beyond their academic skill sets.

The science students had to synthesize a variety of content from their own majors to ensure that the activity book represented a valid slice of evolutionary history. Fossil identification, basic botanical terminology, plant life cycles, and plant evolution were blended together to create exercises that were logical, developmentally appropriate, and content accurate. In order to create the age-appropriate lessons for the book, students were obligated to master pedagogical knowledge, as well.

One student author attended an American Society of Plant Biology meeting in her senior year, competing for honors with another DRC student whose project was much more traditionally science-focused. These students tied for first place in the competition, with the judges' comments highlighting the level of learning and plant biology content the author was able to portray in her book. The student relates, "from the science side I learned a lot about the physiology of plants...[but] I also learned how to break down complex topics within biology to a more general level of understanding. As far as the graphic art side of things, I learned about creating something that can be used in bulk production/print." She speaks to the importance of the kind of learning that took her deeply into her discipline, but also required her to learn a wide cross-section of skills 
and content that were completely new: "Really the entire process of creating the book from sophomore year to senior year is the perfect way to summarize my entire undergraduate education." This author's reflective comment suggests that she found her work on the book full of so many deep and wide learning experiences that it became a metaphor for her whole educational process.

Transference of knowledge from prior classes was integral to creation of the fantasy novels, too. For example, one novel author states that "[descriptively] nailing down the scent of dragon blood because of one of [the] lessons in my first fiction writing class ... I was pulling on everything they'd taught me to have not only the best portfolio I could have, but because there were already plans for this [series] beyond the portfolio."

One of the history activity book authors reported that he had to think "strategically to place complicated content...so that it flowed well with the story without confusing the reader." He could not stop at the level of knowing his history content moderately well; he had to know it so deeply that he could ponder how another less experienced learner would interact and possibly be confused by that material, and then plan instructive narrative around that potential.

\section{Book Production as a Skill Builder}

In addition to disciplinary content, authors learned ancillary skills. The author of one of the fiction series books reported learning "research skills" which allowed her to find "new sources and a deeper body of knowledge within those sources, including content (geography, folklore, and modern African culture), the ability to connect to other projects, and communication skills." She felt these "new sources" gave her the information she needed to open up unique avenues of thinking for other DRC members, allowing them to reach beyond more traditional lore sites of the United Kingdom and Asia for their dragon work. Talking about her own work in the weekly meetings with the team "made [her] want to do more, not competitively, but because of the synergy; after a meeting, [she] wanted to go home and write as much as [she] could." The science activity book author also spoke to the accountability factor of the weekly meetings providing a competitive drive for her to get things done first.

Collaboration became a real-world skill ingrained in all of the projects. Students were forced to interact with unique situations and diverse people, generating communications and group decisions they would not likely have experienced in a more traditional project setting. The science activity book author worked alongside a previous student to ensure she understood the specimen represented in his traditional scientific illustrations as she was taking a class in Media Design. She used this opportunity to 
transfer her line drawings into a digital format suggested by her design professor. The previous art/biology student provided feedback for the merging of this work. As the characters developed and the scenarios for the activities were created, the authors worked alongside a pedagogy specialist and a scientist to ensure accurate content, but they also requested the input of the other DRC undergraduates. Characters were tweaked and scenes changed based on peer feedback. The lead author's response to this critical feedback was not always positive and would sometimes result in a decrease in productivity. Eventually when her peers questioned her, holding her accountable and being genuinely interested, productivity increased. By the end of the project, the author suggested that her overall success came from the foundational teamwork; collaboration providing the needed energy during difficult creative times.

Collaboration was also the cornerstone of the fiction book authors' work. They reported that working within a tight narrative structure, particularly one that was codependent on another's work, was challenging, but it facilitated conceptual thinking. Knowing where each chapter had to be geographically located allowed the authors to connect this information to the plot of each chapter and to the characteristics of the dragons in each book series. For example, in an early chapter of the children's book, the protagonist, Choolew, meets a dragon from The Gambia whose presence is said to prophesy death. In a later chapter, Choolew travels to the underworld to meet an Egyptian dragon and essentially "dies." Had Choolew's adventures taken her to Egypt before The Gambia, the dragon she meets there would have had no impact on the story because Choolew would not have benefitted from the Gambian knowledge. The "word sprints" used by these authors facilitated progress by keeping them on task, allowing them to work through times when ideas were not freely flowing. This active writing served to free their thinking, leading to deeper plot and character development, as well as bigger picture issues such as metaphors that carried across the series.

The act of researching and revising the narrative structures was recursive and gave rise to fresh interconnections with each iteration. Characters were fleshed out through historical research, linguistic detail gathered through language inquiry. The authors made revisions consistent with the confines of the folklore. The resultant texts are truly hybrids, unique renderings of fantasy and real geographies, fiction made more deeply meaningful by the study of what happens to nations under war and colonization, nations undergoing paradigm shifts in knowledge, and individual beings who are agents in these formations of crucial identities. All of these were a part of the learning required to complete the books.

Incorporating the connections among art, technology, and publishing, the science activity book author worked with several different software programs to develop her art before she was finally happy with the outcome. Through that process, she struggled 
with technology and program limitations. Her artistic eye kept pushing to find alternative software programs to ensure the final product matched her expectations. This need for perfection created some tension in meeting deadlines and between key players. Other authors used similar processes as they learned how to best represent the various sections of their books in regard to text fonts, page layout, and typesetting. Students successfully presented their books to the publication department of the state natural history museum. One student's comments reveal the emotional connection and perfectionism related to the experience, "[i]t was surreal; we liked to say in class that projects are never finished, merely abandoned at the deadline, and I had never felt that more than with this project."

One of the history activity book authors used his experience in story and character development in his summer job with a national war memorial. Originally hired solely to lead tours, he became interested in how the tour information was created and delivered. That interest led to the opportunity to write new tour programs and scripts using narratives he developed from primary source documents. He returned to school with a new awareness of how his history degree might be used in his life after graduation: "I never realized there were so many different careers related to history; creating the book gave me the confidence to try my hand at the creative side of things." This broadening continued through the pedagogical side of the project as well. The author has decided to pursue interdisciplinary education graduate study that is "thinktank oriented" so that he may continue in the kind of learning environment he found with this project.

The publishing aspect of the book creation process revealed the need for many different skills as noted by one of the book series authors. Formatting text and art, writing the supplemental information, and learning the standard publication guidelines are "a whole other monster," one that is now her responsibility alone as she is no longer a student member of the team, but a scholar/author. She is finding these skills particularly useful, and still in process, as she works on the new book in her series.

The real-world learning followed the student authors into their work beyond of the DRC. One student recently completed her Master of Fine Arts (MFA) and reports that the "in-depth research skills she learned helped with her thesis development" and that she handled her workload and felt she "belonged in graduate school" because of the time management skills she had learned during the research, revision, and presentation of the DRC book project. Completing her book as an undergraduate student "confirmed" that she was an author and allowed her to "step into the author world earlier" than many of her MFA classmates. 
Another DRC author is currently attending graduate school for a Master's of Science in Education. Her time as an undergraduate designing pedagogy around scientific content intrigued her enough to continue along these lines professionally. She is exploring not only teaching but administration. The DRC provided a structured opportunity for her to explore her interests and continues to support her - she is shadowing the team leaders in the classroom while in graduate school. The long standing bonds among the DRC members, create a lasting, unique professional network.

\section{Discussion}

\section{Ownership, Authenticity, and Transformation}

Take home message: the skills and content knowledge acquired while working on a book-length project reach far beyond any one domain! If this kind of deeper conceptual learning is the goal, book creation and publication is a valid way to get there (Graves, 1984; Wess, 1980). The ownership of the learning is implicit and the authenticity of a real world audience facilitates the transformational learning experience (Beers, 2000; Ensio \& Boxeth, 2000; Odell, 1980; Yenca, 2014). All of the student authors in this case study were a part of an original research project investigating a plant fossil-dragon folklore connection. That inquiry evolved along an organic pathway for each student but was continually supported and impacted by the larger research team. This collective, transdisciplinary massaging of ideas shaped each book, allowing the authors to gain from the brain trust of the group (Emig, 1977; McGregor, 2015).

The transdisciplinary process subsumes the idea that knowledge and skills are integrally tied to one another; the learning occurring in the disciplinary gaps and in the crossing back and forth over them (Klein, 2013; McGregor, 2015). Book production, given the depth and breadth it entails, is a long and laborious process. It requires the author to internalize facts until they become second nature, to learn diverse and seemingly unconnected skills, to take responsibility for all parts of the learning process (Bean, 2011; Emig, 1988; Michigan State University, 2016).

Though it mirrors doing research for an essay or article, the difference is that the final product is a multi-faceted, conceptually whole entity, and the student author owns it. The books that are the focus of this article are examples of the depth and breadth of content knowledge and skill sets that students acquired in their production. The science activity book dives deeply into plant anatomy and evolution. The fantasy fiction books reach out to create something new from lore that is tangentially related to the fossilfolklore question. The history activity book reach beyond fact recognition to pull the 
reader into 14th century political and religious society and the passion of the Civil Rights movement.

\section{Transdisciplinary Pedagogical Power}

The pedagogical success of book production is well-known in the $\mathrm{K}-12$ environment (Fernhaber, Albert, \& Lupton, 2015; Ljung, Szedeli, Guth, \& Nelms, 1993). Good pedagogical techniques are transferable and applicable at many developmental levels with some tweaking of student expectations (Bean, 2011; Dartmouth, 2016). The first grader is appropriately proud of their self-authored picture book and wants to learn how to read more quickly so that they can add text. The same motivation is true of the college student who is intrigued enough by a topic to complete a long, sometimes arduous project because they understand that they own it and all the knowledge that grows from it. In each case, the student is empowered by the pursuit of, and triumph over, new knowledge.

STEM fields have begun to embrace the art communities as a way to engage student learning. When this is accomplished, STEAM, the process of the sciences working synergistically with the arts provides an interdisciplinary platform for scientific literacy (Feldman, 2015; Pyle, 2000; Winrich, 1991). Only one of our case study student projects was actually rooted in the sciences, but all of them connected back to the main DRC project's scientific hypothesis. Students worked across their comfort zones and embraced each other's projects, admitting that after so many opportunities to weigh in on collaborative discussions and processes that they eventually forgot whether individuals were originally working on science, humanities, or social science endeavors. The disciplinary boundaries ceased to matter, though the disciplinary expertise was not minimized (Stoneman, Poli, \& Dooley, 2015).

The books created during this case study may appear rooted in the liberal arts undergraduate environment, but they are equally applicable to other higher education settings. The call from The President's Council of Advisors on Science and Technology (2012) and Partnership for 21st Century Learning (2016) to educate undergrads in a more holistic way was met through these projects. Data suggest collaboration, communication, writing, problem-solving, and pedagogical skills were attained by the student authors. Furthermore, the authors exhibited the ability to follow through with a long-term project and to synthesize disparate information even carrying the learning into the world beyond academia.

The power that results from such transdisciplinary learning is transformational. It connects students with the outside world while providing the safety net and support of 
the education institution. One of the student authors sums it up well: "let me tell you, getting to hold a physical copy of my book in my hand for the first time is the greatest feeling in the world. Nothing compares." 


\section{Acknowledgements}

The authors would like to thank the Virginia Museum of Natural History for their continued support of the Dragon Research Collaborative. This paper would not have been possible without the hard work of the student authors, the artists, and all of the other DRC team members. Thank you! 


\section{REFERENCES}

American Association for the Advancement of Science. (2011). Vision and change in undergraduate biology education: A call to action. Washington, DC: Author.

Bean, J. (2011). Engaging ideas: The professor's guide to integrating writing, critical thinking, and active learning in the classroom (2nd ed.) San Francisco, CA: Jossey-Bass.

Beers, K. (2000). The power of publication. Voices from the Middle, 8(1), 4-7.

Brenson, S. \& Carter, G. S. (1995). Changing assessment practices in science and mathematics. School Science and Mathematics, 95(4), 182-186.

Calkins, L. M. (1991). Living between the lines. Portsmouth, NH: Heinemann.

Calkins, L. M. (1994). The art of teaching writing. Portsmouth, NH: Heinemann.

Conter, R., Lumpkin, T., Poli, DB. \& Stoneman, L. (2017). The dragon's guide to plant evolution. Martinsville, VA: Virginia Museum of Natural History. Print.

Courlander, H. (1996). A treasury of African folklore: The oral literature, traditions, myths, legends, epics, tales, recollections, wisdom, sayings and humor of Africa. New York: Marlowe \& Co.

Dartmouth College. (2016). Collaborative learning/learning with peers. Institute for Writing and Rhetoric. Retrieved from https://writing-speech.dartmouth.edu/ teaching/first-year-writing-pedagogies-methods-design/collaborativelearninglearning-peers

Emig, J. (1988). Writing as a mode of learning. In G. Tate \& E. P. J. Corbett (Eds.), The writing teacher's sourcebook (2nd ed.) (pp. 85-93.). New York: Oxford U. P.

Emig, J. (1977). Writing as a mode of learning. College Composition and Communication, 28(2), 122-128.

Ensio, T. C. \& Boxeth, K. R. (2000). The effects of publishing on student attitude toward writing. ERIC Research Report. [ED 448 471]. Charlottesville, VA: University of Virginia. 
Feldman, A. (2015). STEAM rising: Why we need to put the arts into STEM education. Slate. Retrieved from http://www.slate.com/articles/technology/future tense/ 2015/06/ steam vs stem why we need to put the arts into stem education.html

Fernhaber, S. A., Albert, E. \& Lupton, A. (2015). Publishing children's books with interdisciplinary teams: Reflecting on student innovation through the lens of Tony Wagner. Journal of Entrepreneurship Education, 18(2), 59-72.

Finnegan, R. (2007). The oral and beyond: doing things with words in Africa. Chicago, IL: University of Chicago Press.

Graham, G. (1995). Learning from art. The British Journal of Aesthetics, 35(1), 26.

Graves, D. (1984). A researcher learns to write. Portsmouth, NH: Heinemann.

Hamilton, D. (1980). Interdisciplinary writing. College English, 41(7), 780-796.

Klein, J. (2010). Creating interdisciplinary cultures: A model for strength and sustainability. San Francisco, CA: John Wiley.

Lawrence, D. P. (1999). The community as text: Using the community for collaborative internet research. English Journal, 89(1): 56-62.

Ljung, E., Szedeli, B., Guth, S., \& Nelms, B. (1993). Publishing student writing. English Journal, 82(2), 1993, 47.

Lucey, T. A., \& Laney, J. D. (2017). False echoes of the past: Using visual art to teach critical thinking about history. A Journal of Educational Strategies, Issues, and Ideas, 90(1), 1-7.

McGregor, S. L. T. \& Volckmann, R. (2011). Transversity. Tuscon, AZ: Integral Publishers.

McGregor, S. L. T. (2015). The Nicolescuian and Zurich approaches to transdisciplinarity. Integral Leadership Review, (April-June), 6-16.

McLeod, S. H. (1988). Strengthening programs for writing across the curriculum. San Francisco, CA: Jossey-Bass. 
Michigan State University. (2016). Student-authored book helps professors be better teachers. Michigan State Today. Retrieved from https://msutoday.msu.edu/news/ 2016/student-authored-book-helps-professors-be-better-teachers/

Moore, R. (1993). Does writing about science improve learning about science? Journal of College Science Teaching, 12(4), 212-217.

Myers, M. Langheim, E., Stoneman, L. \& Poli, DB. (2019, in prep).

National Research Council. (2012). Discipline-based education research: Understanding and improving learning in undergraduate science and engineering. Washington, DC: The National Academies Press. doi: $10.17226 / 13362$.

National Survey of Student Engagement. (2008). Promoting engagement for all students: The imperative to look within. Retrieved from http://nsse.iub.edu/ NSSE 2008 Results/docs/withhold/NSSE2008 Results revised 11-14-2008.pdf

Odell, L. (1980). The process of writing and the process of learning. College Composition and Communication, 31(1), 42-50.

Partnership for 21st Century Learning. (2016). Framework for 21st century learning. Retrieved from http://www.P21.org.

Poli, DB. \& Stoneman, L. (2017). Drawing new boundaries: Finding the origins of dragons in Carboniferous plant fossils. Leonardo. doi: 10.1162/LEON_a_01576.

Poli, DB. \& Stoneman, L. (2018). Capturing the transdisciplinary dragon: Creating a crossover natural history-art exhibit. The Atlas, 9, 44-56. doi: $10.22545 / 2018 / 00101$

President's Council of Advisors on Science and Technology. (2012). Engage to excel: Producing one million additional college graduates with degrees in science, technology, engineering, and mathematics. Report to the President. Washington, DC: Author. Retrieved from https://obamawhitehouse.archives.gov/sites/default/ files/microsites/ostp/pcast-engage-to-excel-final_2-25-12.pdf

Pyle, C. M. (2000). Art as science: Scientific illustration, 1490-1670 in drawing, woodcut and copper plate. Endeavour, 24(2), 69-75. 
Reynolds, J. A., Thaiss, C., Katkin, W., \& Thompson, R. J. (2012). Writing-to-learn in undergraduate science education: A community-based, conceptually driven approach. CBE Life Science Educator, 11(1), 17-25. doi:10.1187/cbe.11-08-0064

Rivard, L. P. (1994). A review of writing to learn in science: Implications for practice and research. Journal of Research in Science Teaching, 31, 969-983.

Sousanis, N. (2015). Unflattening. Cambridge, MA: Harvard University Press.

Stoneman, L., Poli, DB. \& Dooley, A. (2015). Hunting dragons: An organic, multidisciplinary pedagogy. In B. Cozza \& P. Blessinger (Eds.), University partnerships for community and school system development (pp. 259-280). Bingley, UK: Emerald Publishing. doi: 10.1108/S2055-364120150000005014.

Wess, R. C. (1980). Publishing student writing: An in-class model. Paper presented at the Annual Meeting of the Conference on College Composition and Communication, Washington, D.C. [Eric Reproduction Services Number ED 185 564].

Winrich, R. A. (1991). Using art to teach science. Cleveland, OH: NASA Lewis Research Center.

Yenca, K. (2014). Book creator student math authors: Take 2. MathyKathy. Retrieved from http://www.mathycathy.com/blog/author/catherine-yencal

Zemelman, S., Daniels, H., \& Hyde, A. (1998). Best practices: New standards for teaching and learning in America's schools. Portsmouth, NH: Heinemann.

Zinsser, W. (1988). Writing to learn. New York: Harper and Row. 